\title{
Hypokalemic Paresis Revealing a Primary Sjögren’s Syndrome
}

\author{
Madiha Mahfoudhi', Hedia Bellali'2, Imen Gorsane', Mounira El Euch'1, Sami Turki', \\ Taieb Ben Abdallah ${ }^{1}$ \\ ${ }^{1}$ Internal Medicine Department, Charles Nicolle Hospital, Tunis, Tunisia \\ ${ }^{2}$ Epidemiology and Statistics Department, Mami Hospital, Ariana, Tunisia \\ Email: madiha mahfoudhi@yahoo.fr
}

Received 16 December 2014; accepted 17 August 2015; published 20 August 2015

Copyright (C) 2015 by authors and Scientific Research Publishing Inc.

This work is licensed under the Creative Commons Attribution International License (CC BY). http://creativecommons.org/licenses/by/4.0/

c) (7) Open Access

\begin{abstract}
Hypokalemic acidosis can complicate a primary Sjögren's syndrome. The clinical feature is rarely revealed by manifestations due to hypokalemia. We report the case of a 46-year-old woman, admitted to explore a paresthesia and paresis of inferior limbs. The diagnosis of Sjögren's syndrome was retained since there was the association of xerophthalmia, sialadenitis at the labial biopsy and positive immunological results (anti-SSA and anti-SSB). The absence of another auto-immune or systemic illness allowed us to consider that the Sjögren's syndrome was primary. The biological explorations revealed a hyperchloremic and hypokalemic acidosis. The treatment was based on corticosteroid and potassium supplementation. The follow-up was marked by a clinical and biological amelioration.
\end{abstract}

\section{Keywords}

Sjögren's Syndrome, Hypokalemia, Interstitial Nephritis, Tubulopathy

\section{Introduction}

The Sjögren's syndrome is a frequent exocrine insufficiency associated to auto-immune systemic anomalies [1]. It's characterized by lymphocytic infiltration of exocrine glands associated with immunological disturbances marked by the production of anti-Ro/SSA and/or anti-La/SSB antibodies.

The most frequent clinical symptoms are oral and ocular dryness, asthenia, arthralgia and pain. However, extraglandular manifestations occurring in third of patients can implicate pulmonary, renal and neurological systems. Its diagnosis may be difficult because of clinical features polymorphism in which the xerophtalmia ans xerostomia can be not revelatory [1] [2].

How to cite this paper: Mahfoudhi, M., Bellali, H., Gorsane, I., El Euch, M., Turki, S. and Abdallah, T.B. (2015) Hypokalemic Paresis Revealing a Primary Sjögren's Syndrome. Open Journal of Internal Medicine, 5, 33-36. 
Many classification criteria were proposed to pose the diagnosis of primary Sjögren's syndrome [1]-[3].

The renal implication corresponds more frequently to tubulo-interstitial nephritis and manifests biologically as hypokalemic acidosis [2]. It's related to renal tubular acidosis. It may constitute an urgence requiring a rapid supplementation to avoid the occurrence of severe paralysis. The isolated renal signs without sicca syndrome lead to a delay in the Sjögren's syndrome diagnosis.

\section{Case Report}

A 46-year-old woman whose complaints were invaliding paresthesia of lower limbs and knee's ache lasting from a month. She presented a sensation of strange bodies in the eyes, an ocular dryness evolving since one year. She didn't receive any treatment.

Physical examination found a paresis of the inferior limbs. The cardiac and respiratory examinations were normal. The hemodynamic parameters were stable with a blood pressure of 120/70 $\mathrm{mmHg}$.

The electrocardiogram signed regular rhythm without flattened or inverted $\mathrm{T}$ waves.

Moreover, the Schirmer and rose Bengal tests were pathologic confirming xerophthalmia.

The biological explorations confirmed a biological inflammatory syndrome with a polyclonal hypergammaglobulinemia, a normochromic normocytic anemia (hemoglobin: $11 \mathrm{~g} / \mathrm{dl}$ ), a hypokalemia of $2.9 \mathrm{mEq} / \mathrm{l}$, a hyperchloremia and a normal level of blood sodium. The level of urine potassium was high $(140 \mathrm{mEq} / \mathrm{l})$. The blood gas (pH: 7.48; $\mathrm{pO}_{2}: 86 \mathrm{~mm} \mathrm{Hg} ; \mathrm{pCO}_{2}: 40 \mathrm{~mm} \mathrm{Hg}$; $\mathrm{SatO}_{2}: 98 \%$; $\mathrm{HCO}_{3}: 29$ ) showed a metabolic acidosis. The renal and hepatic functions were also normal.

The immunological investigations showed a high titer of anti-nuclear anti-bodies (1/1800) with positivity of Rheumatoid Factor, anti-SSA and anti-SSB.

The accessory salivary gland biopsy found a lymphocytic sialadenitis concluding to a stage 4 of Chisholm.

The conventional radiographs of the chest and the knees were normal.

The abdominal echography didn't mention any anomalies especially there were no kidney calcium deposits (nephrocalcinosis).

The thoracic CT scan didn't sign an interstitial lung disease.

The functional respiratory explorations were without abnormalities.

A renal tubulopathy was suspected. The kidney biopsy had objectified tubulo-interstitial nephritis with lymphoplasmocyte infiltrates.

The diagnosis of a primary Sjögren's syndrome complicated of tubulo-interstitial nephritis was confirmed.

The treatment was based on oral potassium supplements, corticosteroids, local ocular treatment.

The clinical follow up was marked by the disappearance of paresthesia, paresis and arthralgias within few days. The hypokalemic acidosis was managed.

\section{Discussion}

The Sjögren's syndrome is an auto-immune disease in which renal disturbances are common. The diagnosis is evident if the the sicca syndrome is patent and revelatory [1]-[3].

Clinical, biological and radiological investigations didn't reveal any other systemic manifestation of the Sjögren's syndrome in our patient. It was considered a primary Sjögren's syndrome since no auto-immune or connective disease was found in our case.

Renal manifestations may be the revealing disturbance. The rate of renal involvement in Sjögren's syndrome ranges from $4 \%$ to $50 \%$.

Primary Sjögren's syndrome is a frequent cause of renal tubulo-interstitial disturbance, in relation with acquired type 1 distal renal tubular acidosis and concentration defects [4].

Two types of renal lesions occurred in patients with Primary Sjögren's syndrome: the most common is interstitial nephritis and rarely glomerulonephritis [4].

Three immunopathologic mechanisms affect the kidney in the Primary Sjögren's syndrome: activated lymphocytes infiltrate tubular epithelium inducing interstitial nephritis, immune-mediated mechanism damaging acid secreting renal cells in the kidney and immune complex-mediated process leading to a glomerulonephritis [4]-[6].

Thus, the renal common lesion in Sjögren's syndrome is interstitial nephritis associated to tubular lesion.

Tubulo-interstitial kidney can be latent limited to histological disturbances or induce type I distal tubular aci- 
dosis. The main manifestations are persistent alkaline urinary $\mathrm{pH}$, hyposthenuria, hyperchloremic hypokalemic metabolic acidosis with anion gap, and nephrolithiasis/nephrocalcinosis [4] [7] [8]. An end-stage renal failure can occur exceptionally in case of a lateness of diagnosis delay.

Kidney biopsies show chronic interstitial nephritis with focal or diffuse plasmo-lymphocytoid infiltration.

Rarely, the proximal renal tubules can be affected, clinically leading to Fanconi's syndrome (type II renal tubular acidosis) [4].

In contrast, glomerulonephritis is less frequent but is usually symptomatic manifesting by hypertension, edema, active urine sediment, proteinuria, and renal insufficiency [4]. The kidney biopsy defines the type of renal lesion [7]-[9].

Hypokalemic acidosis can be sometimes revelatory of the clinical feature.

There was no significant association between kidney disturbance in Sjögren's syndrome and the other systemic complications.

A patent feature is rare, consisting of paresthesia, paresis or paralysis, was published in limited cases [10]-[12]. The diagnosis of Sjögren's syndrome is difficult if the hypokalemia's symptoms are not associated to a patent sicca syndrome or precede sicca symptoms.

Hattori N et al. reported two cases of hypokalemic paralysis complicating a Sjögren's syndrome. The first was a 68-year-old man having hydronephrosis due to ureteral stones and increasing muscle weakness. The second was a 30-year-old woman presenting rapidly progressive quadriparesis [11].

Besides, two cases of paralysis due to hypokalemia complicating a primary Sjögren's syndrome nephropathy were published; Khandelwal D et al concluded then that Sjögren's syndrome should be evoked in patients with inexplained hypokalemic paralysis [12].

The treatment was based in all publications on potassium supplement, and corticoticotherapy for the active interstitial nephritis [10] [13]-[16]. The lateness of diagnosis can threat the prognosis [15] [16]. Only rapid and efficient treatment avoids paralysis complication.

The evolving was good in our patient and comparable to the cases reported in the literature.

The prognosis varies for patients affected by primary Sjögren's syndrome with renal involvement and depends on the type of nephropathy. Patients with interstitial nephritis have a favorable prognosis clinical outcome if a rapid and efficient medical treatment is well conducted, while patients with glomerulonephritis have high risk of developing lymphoma and poor survival [4].

\section{Conclusion}

The kidney involvement in Sjögren's syndrome can present as hypokalemic paralysis in the absence of significant sicca symptoms or may precede sicca symptoms. Sjögren's syndrome should be researched in a case of inexplained hypokalemic paralysis, even in the absence of the sicca syndrome.

\section{Disclosure Statement}

The authors have nothing to disclose.

\section{References}

[1] Vitali, C. (2003) Classification Criteria for Sjögren's Syndrome. Annals of the Rheumatic Diseases, 62, 994-995. http://dx.doi.org/10.1136/ard.62.1.94

[2] Vitali, C., Bombardieri, S., Jonsson, R., Moutsopoulos, H.M., Alexander, E.L., Carsons, S.E., et al. (2002) Classification Criteria for Sjögren's Syndrome: A Revised Version of the European Criteria Proposed by the American-European Consensus Group. Annals of the Rheumatic Diseases, 61, 554-558. http://dx.doi.org/10.1136/ard.61.6.554

[3] Varoquier, C., Salmon, J.-H., Sibilia, J. and Gottenberg, J-E. (2013) Classification Criteria for Sjögren's Syndrome. Revue du Rhumatisme Monographies, 80, 20-25 http://dx.doi.org/10.1016/j.monrhu.2012.11.001

[4] Goules, A.V., Tatouli, I.P., Moutsopoulos, H.M. and Tzioufas, A.G. (2013) Clinically Significant Renal Involvement in Primary Sjögren's Syndrome: Clinical Presentation and Outcome. Arthritis \& Rheumatology, 65, 2945-2453. http://dx.doi.org/10.1002/art.38100

[5] Matsumura, R., Kondo, Y., Sugiyama, T., Sueishi, M., Koike, T., Takabayashi, K., et al. (1988) Immunohistochemical Identification of Infiltrating Mononuclear Cells in Tubulointerstitial Nephritis Associated with Sjögren's Syndrome. Clinical Nephrology, 30, 335-340. 
[6] Moutsopoulos, H.M., Balow, J.E., Lawley, T.J., Stahl, N.I., Antonovych, T.T. and Chused, T.M. (1978) Immune Complex Glomerulonephritis in Sicca Syndrome. American Journal of Medicine, 64, 955-960. http://dx.doi.org/10.1016/0002-9343(78)90449-7

[7] Ren, H., Wang, W.M., Chen, X.N., Zhang, W., Pan, X.-X., Wang, X.-L., et al. (2008) Renal Involvement and Follow-Up of 130 Patients with Primary Sjögren's Syndrome. The Journal of Rheumatology, 35, 278-284.

[8] Bossini, N., Savoldi, S., Franceschini, F., Mombelloni, S., Baronio, M., Cavazzana, I., et al. (2001) Clinical and Morphological Features of Kidney Involvement in Primary Sjögren's Syndrome. Nephrology Dialysis Transplantation, 16, 2328-2336. http://dx.doi.org/10.1093/ndt/16.12.2328

[9] Goules, A., Masouridi, S., Tzioufas, A.G., Ioannidis, J.P., Skopouli, F.N. and Moutsopoulos, H.M. (2000) Clinically Significant and Biopsy-Documented Renal Involvement in Primary Sjögren's Syndrome. Medicine (Baltimore), 79, 241-249. http://dx.doi.org/10.1097/00005792-200007000-00005

[10] Soy, M., Pamuk, O.N., Gerenli, M. and Celik, Y. (2005) A Primary Sjögren's Syndrome Patient with Distal Renal Tubular Acidosis, Who Presented with Symptoms of Hypokalemic Periodic Paralysis: Report of a Case Study and Review of the Literature. Rheumatology International, 26, 86-89. http://dx.doi.org/10.1007/s00296-005-0587-9

[11] Hattori, N., Hino, M., Ishihara, T., Moridera, K., Ikekubo, K. and Kurahachi, H. (1992) Hypokalemic Paralysis Associated with Distal Renal Tubular Acidosis. Internal Medicine, 31, 662-665.

[12] Khandelwal, D., Bhattacharya, S., Khadgawat, R., Kaur, S., Tandon, N. and Ammini, A.C. (2012) Hypokalemic Paralysis as a Presenting Manifestation of Primary Sjögren's Syndrome: A Report of Two Cases. Indian Journal of Endocrinology and Metabolism, 16, 853-855. http://dx.doi.org/10.4103/2230-8210.100684

[13] Rao, N., John, M., Thomas, N., Rajaratnam, S. and Seshadri, M.S. (2006) Aetiological, Clinical and Metabolic Profile of Hypokalaemic Periodic Paralysis in Adults: A Single-Centre Experience. The National Medical Journal of India, 19, 246-249.

[14] Morović-Vergles, J., Galesić, K. and Vergles, D. (2007) Primary Sjogren's Syndrome Presenting as Hypokalemic Paralysis. Annals of Saudi Medicine, 27, 125-127. http://dx.doi.org/10.4103/0256-4947.51532

[15] Toy, W.C. and Jasin, H.E. (2008) An Unusual Case of Hypokalemic Paralysis Associated with Primary Sjogren's Syndrome. The Journal of the Arkansas Medical Society, 104, 286-287.

[16] Baaj, M., Safi, S., Hassikou, H., Tabache, F., Mouden, K. and Hadri, L. (2010) Hypokalemic Paralysis Revealing Sjögren's Syndrome Associated with Auto-Immune Thyroiditis. Journal of Nephrology \& Therapeutics, 6, 52-56. http://dx.doi.org/10.1016/j.nephro.2009.09.002 